dress that which many volumes can not contain. It is believed, however, that sufficient has been presented to lead to the conclusion that the early diagnosis of the affection under consideration presents no insurmountable difficulties, and that the application of a reasonable amount of care and skill, and in a few cases allowing the lapse of a little time, will almost invariably lead to correct results. In attaining these ends no portion of our experience concerning pulmonary tuberculosis can be neglected, but particular attention should be given the points mentioned.

4571 Lake Avenue.

\section{THE SIGHT AND HEARING OF SCHOOL CHILDREN.*}

BY H. V. WURDEMANN, M.D.

Ophthalmic and Aural Surgeon to the Milwaukee Children's Hospital and to the Milwaukee County Hospital for the Chronic

Insane; Managing Editor, Annals of Ophthalmology ; Associate Editor, Ophthalmic Record; Chairman, Section on Ophthalmology, American Medical Association, 1900 , etc.

MILWAUKEE, WIS.

WITH THE COLLABORATION OF

FRANK ALLPORT, M.D.

Professor of Ophthalmology, Chicago Policlinic; Professor of Oph thalmology and Otology, Northwestern Woman's Medical Col-

lege ; Oculist and Aurist to St. Luke's Hospital, Consulting Oculist and Aurist to St. Joseph's Hospital. clicago.

I have been requested by the superintendent of the Milwaukee schools to say something concerning methods for the systematic examination of school children's vision and hearing, which have been instituted in a number of the large cities of America, and have been taken up in this city under the authority of the commissioner of public health.

The enlightemment of the young may be likened to the raising of agricultural products. Not only are proper seeds necessary, but favorable soil and conditions are quite as needful. The means of education: the buildings, properly placed, constructed and conducted, including teachers, systems, books, etc., have been fully developed in our day. The child's mind should be active and its body and senses healthy to render it capable of profiting by instruction. Modern schools, with their effective machinery, are a source of gratification and delight to all; but enthusiastic, progressive and systematic educators do not always consider the soil on which the seed of enlightenment falls ; in other words they are disposed to consider children as a massed entity, do not separate them into isolated individuals, with distinct inheritances, and mental and physical peculiarities, rendering them more or less adaptable to the requirements of the modern public school. Children are thrown into the great machinery of school life, are divided into grades, are expected to adhere to them and become educated according to this system. A child may have a weak or crooked back, which will become aggravated by close confinement at improperly constructed desks; he may have lungs handicapped with the incipient germs of consumption, encouraged by the protracted inhalation of vitiated school air; he may languish from an impoverished condition of the blood, and pine and droop under too much study and too little fresh air.

These are some of the conditions noticed in school children, militating against the easy acquirement of an education; but more directly detrimental is the existence

*An Address delivered before the Principals of the Milwaukee Public Schools, Jan. 12, 1900. of certain abnormal conditions of the organs of special sense, of seeing and hearing, which are certainly of prime importance in acquiring an education. If a child can not see well and hear well his position is certainly most unfortunate in the modern public school, where he is expected to keep up with his grade work, or else subject himself to chagrin and mortification. Do not understand me as saying that your schools are to be likened to the car of Juggernaut, that ruthlessly throws down and crushes all who unfortunately come in contact with its destroying wheels. Far from it. I fully appreciate the gentle, humane and sympathetic feelings that proceed from the hearts of most teachers toward the children committed to their care. I am not unaware of their watchfulness and solicitude over their little flock, that prompts them to change the seats of the deaf and nearsighted, to make allowances for any noticeable physical or mental short-comings, to frequently visit parents and urge on them the necessity of action concerming the health of a child; but these are isolated though frequent instances, inspired by individual sympathy and character.

What we want is a paternal school system of health investigation, by which the physical defects of children will be made manifest and steps taken to protect pupils against themselves and in many instances against their parents. We also want a system that, after these unfortunate conditions have been discovered, will not only allow, but insist on, the harmonizing of the studies to the child, and not the child to the studies. I am not unaware of how often this is done; that the doctor's certificate of poor health is usually respected; that the course of study is sometimes changed under the advice of parents or teacher. I think I am not wrong in saying that these changes are so frequent, and so little encouraged, that children will often endure much physical discomfort or even suffering, rather than assume the mortification brought on them by the distinction of a grade change. These changes should be inspired from the intelligent illumination of regular physical examinations, and should be so common as to excite no comment, and give rise to no loss of a pupil's self-respect, or disappointment on the part of the parent, who frequently allows a child to languish and acquire permanent invalidism, rather than interfere with his class standing, or the date of a projected graduation.

I would not be misunderstood as advocating the abolition of systems and grades. It is needless to say that schools can not be properly conducted on other principles. Neither do I advocate the indiscriminate changing of children in grades, without just and adequate consideration. Neither do I ignore the fact that pupils are frequently changed to other grades for ostensibly good and sufficient reasons. I advocate more system and more grades. I advocate a system of physical examination in schools, by which we may know the condition of a child's health, and not trust chance or circumstances to detect it, and I advocate more and shifting grades, commensurate with the physical condition of defective children. In other words, 1 do not believe in the wholesale education of the rising generation, which is our country's hope, its bulwark and defense, and whose physical and mental condition is a sacred trust which we must guard and cherish. I do not believe in thrusting these little, yielding, impressionable, often sickly, lives into the common crucible, to be moulded and turned out with identical exactitude and precision. I believe that children should not be damaged by their educational existence, but should emerge from the portals of the Amer- 
ican public school in better physical, mental and, may I say, moral condition than when they were entrusted to its fostering care, and that steps should be taken calculated to bring about the fulfilment of this imperative duty.

We must creep before we walk, and a great reform of this kind can not be accomplished without primitive and pioneer work. The eye is the most important physical element in the acquirement of an education, unless it be the brain, and is fortunately an organ capable of ready examination. The testing of school children's eyes has been systematically performed for many years in Europe, and especially in Germany-that factory of bad eyesand, since 1895, somewhat in this country, but these examinations have been made by oculists appointed by school authorities, who have personally-with their assistants--examined every child in a given community. This system operated very well in monarchical Europe, accustomed to arbitrary domination, but in America, habituated to democratic rule and individual freeedom, the method has given rise to much opposition from parents, children, school authorities and other oculists wherever tried. In fact, the method has been forcibly discontinued, as an element of too much discord and professional strife. Teachers have, sometimes, in a spirit of righteous investigation, made abortive attempts at testing their school children's eyes in various more or less scientific fashions, being forced by intelligent observation to a realization of the truth that many children were struggling under an ocular burden, very heavy to carry.

A systematic method for the examination of pupils' eyes by teachers, comprising simple questions and instructions which, if properly carried out, will detect the existence of most important ocular diseases, has been in use in Minneapolis and St. Paul; Worcester, Mass.; Sycamore, Ill.; Philadelphia and Chicago, for several years, and is being introduced in San Francisco and other cities.

Statistics show the average frequency of defective eyes in American school children to range from 25 to 35 per cent. When it is remembered that the vast majority of these have never sought ophthalmic advice, and are therefore endeavoring to acquire an education under exceedingly disadvantageous circumstances, the importance of this subject can be imagined. Time forbids me to enter into any description of the ocular diseases and conditions chiefly incidental to school life, but you doubtless know that nearsightedness or myopia is quite frequently a development caused by excessive study under poor conditions; that hyperopia and astigmatism are malformations of the eyeball, rendering study exceedingly irksoine, because of tired eyes and head and headache; that a cataract is an opacity of the crystalline lens, and may exist and partly blind a child, without recognition, except by skilful examination; that optic nerve, choroidal and retinal inflammations may occur without especially noticeable symptoms to an observant child; that many varieties of "sore eyes" may hinder even reasonable school diligence; in short, that many morbid ocular conditions may obtain without attracting especial attention, and render the acquirement of an education exceedingly burdensome to children who thereby acquire the reputacion of being dull, stupid and idle, but whose unenviable record may be completely revolutionized by proper ocular treatment and advice. The same may be said of aural diseases or conditions attended by deafness.

These are the children we hope to reach by these school tests, and especially those poor and almost abandoned children, whose parents are ignorant, careless and indifferent to the physical conditions of their offspring. These eye tests are now quite generally recognized as being the best practical solution of the question as to how to place children in the proper channel to secure relief from ocular complaints, and as the idea is firmly established, we think that the time is rife for another advance in the physical examination of the children.

Many children suffer from nasal obstructions and particularly from enlargement and engorgement of the

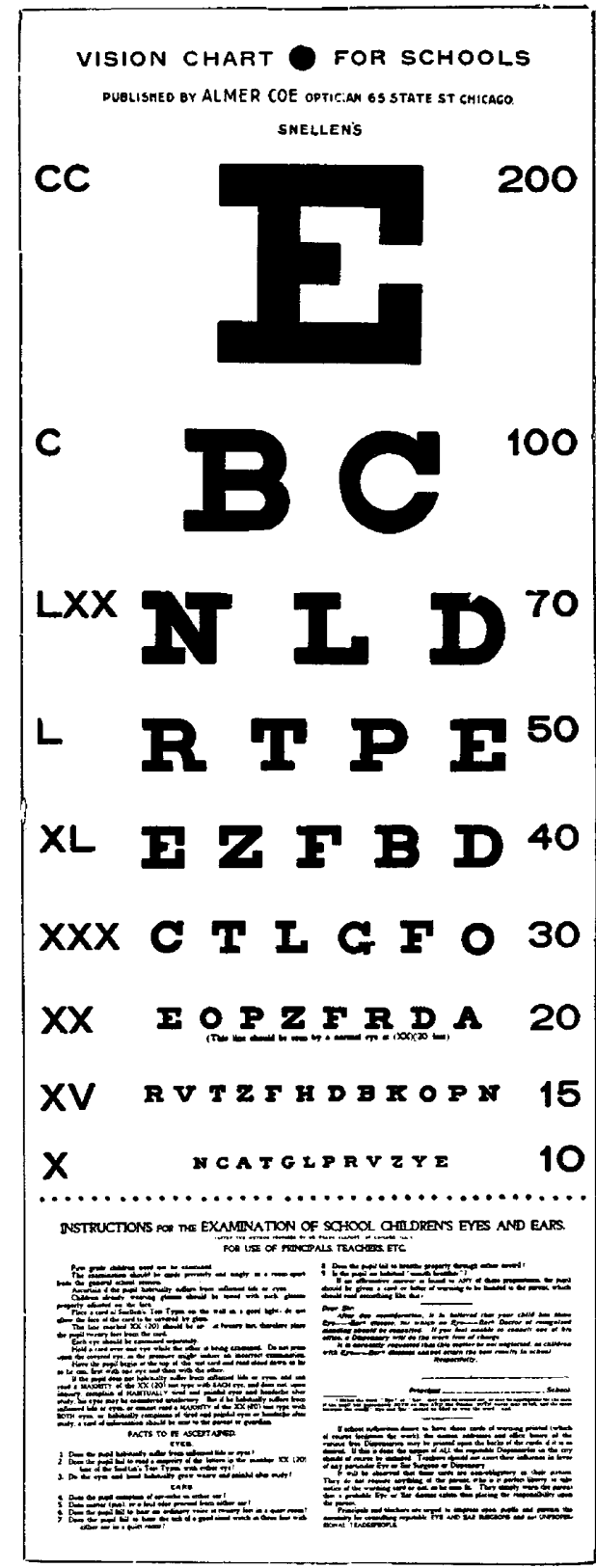

tissues in the upper part of the pharynx and throat. Such obstructions prevent free nasal breathing and cause a utilization of the mouth for this purpose, besides giving rise to deafness, on account of a lack of proper aeration of the middle ear through the Eustachian tubes, leading from the upper portion of the throat to the ear. These enlargements in the pharynx, called "adenoid growths or vegetations," are productive of a large majority of the chronic ear diseases from which children suffer. Fortunately they can be easily removed, and some of the most satisfactory surgical work ever witnessed follows such operations. These children, called "mouth breath- 
ers," present a peculiarly dull and stupid appearance which is aggravated by the almost invariably accompanying deafness. Removal of the growths and proper treatment to the ears completely revolutionize the appearance and character of the child, and if you have ever observed such physical and mental transformations, you will never forget them, nor fail to emphasize the importance of such work.

One important matter should be remembered in these tests, viz.: They are not conducted solely for the purpose of detecting ocular conditions requiring the use of glasses. Many seem to have the idea that they simply detect errors of refraction, but such is not the case, as they will, if properly carried out, detect the existence of almost all serious ocular diseases or conditions. The teacher does not know what disease is present, but that something is wrong; that is sufficient. The sole idea in the tests is to separate those children having good eyes and ears from the defectives. These tests should be made at the beginning of the school year, statistical reports prepared and reports of the defectives again made at the end of the school year. Those passing the tests successfully are returned to school and not re-examined for one year, when they should undergo another examination, as morbid conditions may have developed meanwhile. Those having defective eyes or ears are simply given a card of warning, which they hand to the parent This card merely states that some eye or ear disease is believed to exist, and the consulting of a physician, therefore, is advised. The matter is not compulsory, as the parent may do as he thinks best; he may consult any physician or dispensary he chooses. In this way the duty is thrown on the shoulders of the parent, where it belongs, but if compliance with the advice is not observed, the teacher may from time to time urge the matter with tact and delicacy, but nothing should be said to make the parents regard the matter as an arbitrary demand.

Many teachers outside of large cities are interested in this work, and are constantly inquiring how they may do it in places where a board has taken no official action along these lines. They may purchase one of these combination charts ${ }^{1}$ for twenty-five cents, containing both the test-types and instructions, and proceed with the work in their room or school. To this there can certainly be no objection, as the tests are absolutely harmless in every particular.

In Minneapolis and Chicago, where these examinations were most complete, we know positively that thousands of children were much benefited by these proceedings. Cataracts were removed, cross-eyes straightened, intraocular inflammation relieved, glasses were fitted, etc.; in short, the tests have really been exceedingly beneficent in their results, and while some opposition from parents and teachers was at first encountered, nothing but commendation can now be heard from all sources.

For the Milwaukee tests the commissioner of public health and the superintendent of public schools have authorized me to design a plan for this investigation, embodying the best features from the experience of other cities. To this means I have secured the collaboration of other oculists, Drs. Charles Zimmermann, J. S. Barnes and N. M. Black, who, with myself will at appointed times instruct the grade teachers in the anatomic and physiologic relations of the eye and ear so far as may :id in these investigations, and will also instruct them in the methods of examination and keeping what records may be needed by actual demonstrations on teachers or

1 Vision Charts for Schools; published by Almer Coe, f5 State St. Chicago. pupils at these meetings. The tests and records will be made by the teachers for each grade, under the supervision of the principals of the school. The number of children examined should be noted, but only complete records of the defectives are to be made, which are to be done in duplicate by the room teachers and both copies sent to the principals, one copy to be kept by the principals and the other sent to my address. The cards of warning are to be filled in and sent by the principals to the parents of any child found defective. At the end of the school year the principals are to fill out the duplicate reports, stating whether or not the pupil has profited by the card of warning to its parents, and the results, as well as his impression of the usefulness of such an examination in his school. This duplicate is then to be sent to my address for nse in the preparation of a report to the school board.

A compound test-card, based on the standard types of Snellen, has been designed by Dr. Frank Allport- "The Visual and Aural Chart for Schools"-and will be used in the Milwaukee examinations. Roman numerals are on one side of each line and Arabic on the other. Under the twenty-foot line are these words: "This line should be seen by a normal eye at 20 (XX) feet," and would seem to make the matter sufficiently plain. Under the ten-foot line, on the card proper, is a half-broken line at which the lower portion of the compound card should be severed from the upper portion. Just under this line are printed the words: "Please detach by breaking on this line."

The card which is thus detached contains the teacher's instructions as to how to proceed with the tests. The upper or long card containing Snellen's types is the testing card, and should be hung on the wall when in use. On the lower card of instructions is printed the following matter, most of which is already familiar to those who have used this method:

$$
\text { TEST CHART. }
$$

Instructions for the Examination of School Children's Eyes and Ears. For Use of Principals and Teachers. After the Method proposed by Dr. Frank Allport of Chicago, Ill.:

First grade children need not be examined.

The examination should be made privately and singly, in a room apart from the general school session.

Ascertain if the pupil habitually suffers from inflamed lids or eyes.

Children already wearing glasses should be tested with such glasses properly adjusted on the face.

Place a card of Snellen's test types on the wall in a good light; do not allow the face of the card to be covered by glass. The line marked $\mathrm{XX}$ (20) should be seen at twenty feet therefore place the pupil twenty feet from the card.

Each eye should be examined separately.

Hold a card over one eye while the other is being examined. Do not press upon the covered eye, as the pressure might induce an incorrect examination.

Have the pupil begin at the top of the test card and read aloud down as far as he can, first with one eye and then with the other.

If the pupil does not habitually sufier from inflamed lids or eyes, and can read a majority of the XX(20) test type with each eye, and does not, upon inquiry, complain of habitually tired and painful eyes and headache after study, his eyes may be considered satisfactory. But if he habitually suffers from inflamed lids or eyes, or can not read a majority of the XX (20) test type with both eyes, or habitually complains of tired and painful eyes or headache after study, a card of information should be sent to the parent or guardian.

\section{FACTS TO BE ASCERTAINED.}

EYES.

1. Does the pupil habitually suffer from inflamed lids or eyes? 
2. Does the pupil fail to read a majority of the letters in the number XX (20) line of the Snellen's test type with either eye.?

3. Do the eyes and head habitually become weary and painful after study?

4. Is the pupil probably cross-eyed?

EARS.

5. Does the pupil complain of ear-ache in either ear?

6. Does matter (pus) or a foul odor proceed from either ear?

7. Does the pupil fail to hear an ordinary voice at twenty feet in a quiet room?

8. Does the pupil fail to hear the tick of a good-sized watch at three feet, with either ear, in a quiet room?

9. Does the pupil fail to breathe properly through either nostril?

10. Is the pupil an habitual "mouth breather"?

If an affirmative answer is found to any of these propositions the pupil should be given a card or letter of warning to be handed to the parent, which should read something like this:

Dear Sir: After due consideration, it is believed that your child has some eye-ear disease, for which an eye-ear doctor of recognized standing should be consulted.

It is earnestly requested that this matter be not neglected, as children with eye-ear diseases can not attain the best results in school

Respectfully...............

Principal......... School

Either the word "eye" or "ear" may here be crossed out, as may be appropriate for the case. If the pupil has presumably both an eye and ear disease, both words may be left, and the space between the words "eye" and "ear" should be filled with the words "and".

It will be observed that these cards are non-obligatory in their nature. They do not require anything of the parent, who is at perfect liberty to take notice of the warning card or not as he sees fit. They simply warn the parent that a probable eye or ear disease exists, thus placing the responsibility upon the parent.

These instructions are repeated in the tabulated reports, and in addition instructions for ear examination as follows:

In a room apart from the general school session examine the pupils singly, ascertaining if the pupil complains of earache, if matter (pus) or a foul odor proceeds from either ear, if the pupil fails to breathe freely through either nostril or if he breathes mostly through his mouth. Have the child turn his back, an assistant plugging up the left ear with a cloth over the finger. The examiner steps away about 20 feet, asks the child a direct question in a low but distinct voice requiring a direct answer. The right ear is then to be stopped and the left ear tested. If after several questions the child fails to hear the spoken words and answers incorrectly he is deemed defective. A good-sized watch is held about six feet away and gradually moved toward the ear to be tested and distance at which the subject says he hears the tick is noted. It should be heard at least three feet away from the ear. If the pupil fails to hear spoken words or the tick of the watch as above noted, if he complains of ear-ache, if pus or a foul odor is observed from either ear, if his nose is habitually stopped or if he is a mouth breather, his name and a detailed report should be entered below on this sheet by the teacher, and a card of information sent by the principal to the parent or guardian.

General suggestions and instructions are likewise found on the tabulated reports as follows:

Examine your entire school by these methods at the begin. ning of the school year; part of the pupils each day, so as not to interfere with the regular course of instruction. Examine each new pupil entering between beginning and end of terms. Only such pupils as are thought necessary to send to an eye or ear physician need tabulation on this blank. This sheet is to be filled in duplicate, both copies sent to your principal, one copy of which is to be sent as soon as you have completed the examination of the school to the commissioner of Health for Milwaukee. The other is to be held until the end of the school term by the principal, who will then send the duplicate copy to this address, noting thereon in the two last columns, whether the pupil consulted a physician, or if not, why; describing the results of treatment, particularly as regards the pupil's conduct, health and application to study.

One of the chief obstacles to satisfactory results in Minneapolis and Chicago was the fact that many parents took their children to jewelers and opticians instead of oculists. The cities were flooded with fulsome advertisements, and circulars from opticians and spectacle peddlers to teachers, parents and physicians soliciting their trade and influence.

This preliminary examination is not proposed simply for the purpose of ascertaining the need of glasses, but in hopes of disclosing existence of almost all ocular diseases. The eye is not merely a mechanical apparatus which, if out of order, requires for its correction a pair of glasses. A good medical education is absolutely essential for the diagnosis and treatment of astigmatism, hyperopia, myopia and imbalance of the ocular muscles; the former of which are malformations, and the latter diseases, which, in many cases, need something else than the placing of lenses before the eye as well, for cure of inflammation and work of a surgical nature.

Principals and teachers are, therefore, urged to impress upon pupils and parents the necessity for consulting reputable eye and ear doctors and not unprofessional tradespeople.

\section{SPECIAL ARTICLE.}

\section{RFLATIONS OF PHARMACY TO THE MEDICAL PROFESSION. \\ III.}

It has been shown that confusion existing in the lay mind, and largely shared by the medical profession, concerning the so-called "patent medicines" for domestic use, is due to the popular incorrect use of the term "patent" to indicate that an article is afforded such protection as rests on priority of registration of a name for the article as a trademark, or through copyright including this. It does not mean the article is protected through letters patent issued on the process of manufacture, or on the composition of the article itself. It has also been shown that a patent is very rarely granted on the combination, or mixtures of various ingredients, or on the process of producing any medicinal preparation or mixture, if for no other reason from the fact that in the vast majority of instances it would be impossible to show any originality, improvement, or invention, even to the often limited extent necessary to satisfy the patent office requirements; hence the almost general reliance on the trade-mark laws, for protection in medicinal articles.

As has already been pointed out, it is not the intent of the trade-mark law to afford protection to the name of an article, but simply through its registration record priority in case of contention over a device, symbol, sign, or figure to distinguish a certain "brand" of manufactures from all other brands.

It is the evident intent of the trade-Inark law to protect a manufacturer through some design of his own invention, which must be arbitrarily selected, or, as it is termed, "fanciful," and in the case of a name it must therefore not be descriptive, i. e., too closely simulate the name of any natural substance, mineral, plant, or animal, or geographic name, or that of any well-defined physical, chemical, physiologic process or mechanical or therapeutic uses. That this is a subject of difficult interpretation is self-evident, and the registration by

* The third of a series of articles to appear weekly in THE JodRNAL designed to correct the abuses from advertising and patronizing phar maceutical specialties. 